\title{
Saúde e evasão escolar de alunos na modalidade Educação de Jovens e Adultos: uma revisão bibliográfica
}

\author{
Health and school dropout of students in the Youth and Adult Education modality: a \\ bibliographic review
}

\author{
Salud y deserción escolar de los estudiantes en la modalidad de Educación de Jóvenes y \\ Adultos: una revisión bibliográfica \\ Carla Ferreira Alves Belonia ${ }^{1 *}$, Sônia Maria da Costa Barreto.
}

\begin{abstract}
RESUMO
Objetivo: Revisar na literatura científica diferentes concepções sobre a evasão escolar na educação de jovens e adultos e como questões de saúde podem influenciar nessa situação. Revisão bibliográfica: A pesquisa foi um estudo bibliográfico dando ênfase a uma abordagem qualitativa que permite um processo investigativo acerca da problemática: quais são as questões de saúde existentes que potencializam a evasão escolar dos alunos na Educação de Jovens e Adultos? Com o resultado deste estudo foi possível identificar as peculiaridades pela qual os alunos da educação de jovens e adultos se evadem, visando amenizar as dificuldades enfrentadas por esses estudantes no processo ensino aprendizagem, apontando políticas de saúde e educação que possibilitem reduzir os números da evasão escolar. Considerações finais: Pode-se concluir que a temática continua sendo um desafio para os educadores, que devem procurar entender os motivos que geram a evasão, dada a multiplicidade de fatores causais. Compete à escola buscar métodos que incentivem o grupo escolar a acolher pessoas e não as afastar devido a problemas do cotidiano, além de ações geradas pelas políticas públicas.
\end{abstract}

Palavras-chave: Educação, Saúde, Evasão escolar.

\begin{abstract}
Objective: To review in the scientific literature different conceptions about school dropout in the education of young people and adults and how health issues can influence this situation. Bibliographic review: The research was a bibliographic study emphasizing a qualitative approach that allows an investigative process on the issue: what are the existing health issues that enhance students' school dropout in Youth and Adult Education? With the result of this study it was possible to identify the peculiarities by which students of youth and adult education evade, aiming to alleviate the difficulties faced by these students in the teaching-learning process, pointing out health and education policies that make it possible to reduce the numbers of school dropouts. Final considerations: It can be concluded that the theme remains a challenge for educators, who must seek to understand the reasons that cause dropout, given the multiplicity of causal factors. It is up to the school to seek methods that encourage the school group to welcome people and not to alienate them due to everyday problems, in addition to actions generated by public policies.
\end{abstract}

Keywords: Education, Health, School dropout.

\section{RESUMEN}

Objetivo: Revisar en la literatura científica diferentes concepciones sobre el abandono escolar en la educación de jóvenes y adultos y cómo los problemas de salud pueden influir en esta situación. Revisión bibliográfica: La investigación fue un estudio bibliográfico que enfatizó un enfoque cualitativo que permite un proceso de investigación sobre el tema: ¿Cuáles son los problemas de salud existentes que potencian la deserción escolar de los estudiantes en Educación de Jóvenes y Adultos? Con el resultado de este estudio se logró identificar las peculiaridades por las que evaden los estudiantes de educación de jóvenes y adultos, con el objetivo de paliar las dificultades que enfrentan estos estudiantes en el proceso de enseñanza-aprendizaje, señalando políticas de salud y educación que permitan reducir el número de deserciones escolares. Consideraciones finales: Se puede concluir que el tema sigue siendo un desafío para los educadores, quienes deben tratar de comprender las razones que generan la deserción, dada la multiplicidad de factores causales. Corresponde a la escuela buscar métodos que incentiven al grupo escolar a acoger a las personas y no alienarlas por problemas cotidianos, además de acciones generadas por las políticas públicas.

Palabras clave: Educación, Salud, Deserción escolar.

1 Faculdade Vale do Cricaré (FVC), São Mateus - ES. *E-mail: xpcarla@hotmail.com 


\section{INTRODUÇÃO}

Hoje, mais do que nunca, a Educação de Jovens e Adultos (EJA) possibilita ao aluno um processo de ensino e aprendizagem que contribui para a sua inserção no mercado de trabalho, bem como um aprendizado contínuo que desenvolva sua capacidade de equacionar problemas na vida social, atrelado à criatividade para enfrentar 0 atual contexto histórico que vivemos.

A modalidade de ensino para jovens e adultos se dispõe a atender estudantes maiores de 15 anos que não conseguiram terminar os estudos em idade regular ou que estão em defasagem série e idade, de acordo com a legislação atual. (TEODORO A, 2011).

Geralmente o público da EJA é composto por pessoas que apresentam problemas econômicos, vítimas de exclusão social, fracasso escolar e baixa autoestima, que os conduzem a abandonar a escola. Muitas vezes, ao retornar, os alunos deparam com um currículo que não atende as suas necessidades, em razão de diversos fatores, entre os quais a oferta de conteúdos que estão fora da sua realidade e o uso de metodologias inapropriadas para o público em pauta (TEODORO A, 2011).

Segundo Ferreira ABH (2010), a evasão é a prática de evadir-se, de esquivar ou fugir de algum local. No entanto, pode-se dizer que a evasão escolar é um problema que afeta todas as formas e todos os níveis de ensino. Esse episódio, caracterizado pelo abandono escolar, também ocorre em detrimento do desenvolvimento pessoal e profissional do indivíduo, por exemplo, a falta de qualificação e de oportunidades de trabalho.

Historicamente, a evasão tem se apresentado como uma das fragilidades do sistema educacional brasileiro. Cientistas e educadores já discutem esse tema há algum tempo, que hoje se destaca como um problema a ser resolvido.

A evasão escolar é um problema não só em algumas unidades escolares, mas também em todo o país e desempenha um papel importante nas discussões no cenário brasileiro para buscar um melhor entendimento da questão (FEREIRA ABH, 2010).

Esse fato se sobressai como ponto para todos os envolvidos, como pais, alunos, professores e instituições de ensino. Apontada como déficit do sistema escolar desde os primeiros estudos sobre essa questão no Brasil, ainda hoje perdura alto índice de evasão.

Para tanto será realizado um levantamento bibliográfico, a fim de contribuir para minimizar a evasão escolar na educação de jovens e adultos, focando em um ponto pertinente, que são questões relacionadas à saúde que podem potencializar a evasão desses alunos do ambiente escolar (FAIAL LCM, et al., 2019).

As mudanças sociais afetaram o processo educacional, seus objetivos, habilidades de estudo e o conteúdo curricular. É geralmente aceito que as escolas de hoje não podem ser mantidas apenas como instituições de alfabetização, mas devem ser responsáveis por centros de socialização, exercendo todo o potencial dos alunos, tornando-os elementos úteis e de adaptação às suas comunidades. Esta é uma tarefa complexa, e recursos e esforços devem ser integrados para mudar a mentalidade por meio da participação ativa da comunidade (FAIAL LCM, et al., 2019).

Sobre as questões que levam ao aluno a evadir-se do ambiente escolar, o bullying é o que toma os maiores espaços no debate, entretanto outras situações relacionadas à saúde devem ser abordadas, desde as que invoquem a saúde mental, situações referentes à gravidez precoce, doenças que dificultam o acesso do aluno ao ensino regular e acabam fazendo com que ele não se sinta confortável no ambiente escolar.

Um exemplo clássico disso, são alunos cegos, surdos ou mudos que não conseguem acompanhar a turma e acabam evadindo do ambiente escolar, isso pode leva-los ao programa de Educação de Jovens e Adultos (EJA), e pode retira-los desse programa sem concluírem seu propósito, a formação na educação básica (MENDES MS, 2013).

Por isso, objetiva-se através deste estudo apresentar propostas que possam solucionar o problema da evasão escolar na Educação de Jovens e Adultos, fomentando estratégias e planos para que o aluno não deixe o ambiente escolar precocemente. Também é objetivo desta revisão, apontar a problemática relacionada à saúde e expor como problemas nessa área podem causar ou potencializar a evasão escolar. 


\section{REVISÃO BIBLIOGRÁFICA}

A EJA é um segmento da educação que representa um caminho e uma possibilidade de desenvolvimento das pessoas de todas as idades, oportunizando os jovens e adultos a atualizarem seus conhecimentos, quando poderão demonstrar suas habilidades, trocar experiências e, com isso, ter acesso a novas formas de trabalho e cultura, porém a evasão escolar tem se apresentado como uma das fragilidades do sistema educacional brasileiro (CEARON NM, 2011).

Cearon NM (2011), ainda confirma que os alunos, ao se matricularem na EJA, têm a intenção de mudar de emprego, considerada prioridade na concepção deles, porque irão melhorar a qualidade de vida e buscar por um trabalho melhor, pois assim teriam condições de vida mais confortável, consequentemente com salário melhor.

O contentamento pessoal é outro ponto importante dos alunos quando adultos ao procurarem a escola à noite, pela satisfação individual de ser uma pessoa detentora de estudo. A satisfação pessoal correlaciona 0 sonho de estudar desde criança, porém com oportunidade somente na vida adulta.

Para Oliveira PCS (2010), a evasão escolar ou abandono é um episódio que tira milhares de estudantes da escola, os quais podem se tornar excluídos da sociedade e do mercado de trabalho no futuro. São problemas importantes enfrentados por gestores e educadores e, portanto, pela sociedade.

Esses indivíduos que, por um motivo ou outro, se evadem ou abandonam a escola farão parte de um grande conjunto de cidadãos com baixa formação educacional em assumir questões fundamentais da vida em sociedade, seja no âmbito pessoal, seja profissional, seja como cidadão. Ao investigar a evasão escolar de alunos trabalhadores na EJA, constata suas possíveis causas e mostra as estratégias pedagógicas sobre 0 acontecimento que vai além do ambiente escolar.

A educação é um direito de todos, devido a isto, os problemas que não permitem os alunos a estarem nas escolas devem ser incorporados a uma linha de políticas públicas que busquem formar um movimento inverso. Problemas que ocasionam a evasão escolar devem ser aprofundados em uma dinâmica de inteiração entre comunidade escolar e sociedade civil, buscando apurar os efeitos e possíveis soluções para tal situação.

Questões peculiares podem ser um grande entrave para que o aluno permaneça no ambiente escolar, quando se trata de jovens e adultos, o problema pode ser maior, já que criou-se um estereótipo de que não se frequenta a escola quando se atinge uma idade elevada (FERNANDES AP e CAIADO KRM, 2015).

Para Filho RBS e Araújo RML (2017), diferentes teorias para resolutivas referentes ao abandono escolar podem ser apontadas. É mencionado na literatura dois tipos de participação: a escolar (educacional ou acadêmica) e a social (que trata de questões afetivas ligadas a docentes, colegas e membros do corpo escolar). Se tratam de duas formas fundamentais que influenciam na decisão de permanecer ou não na escola.

Para tal, existem outros motivos que levam a evitar suspeitas e podem ser classificados de acordo com os fatores determinantes: (i) escola (pouco atraente, autoritária, com professores despreparados, inadequados e desmotivados); (II) estudante (desinteressada, indisciplinada, com problemas de saúde, gravidez); (III) pais ou responsáveis (não observadores, não interessados no destino de seus filhos); (IV) social (trabalhar com planos de estudos incompatíveis, agressão entre alunos, violência contra gangues, etc.).

A educação formal é reconhecida como fator de proteção pela inclusão social que promove a estabilidade dos jovens na escola e reduz o risco de maternidade precoce, vinculando a gravidez na adolescência ao abandono escolar precoce. Em 2014, cerca de 1/3 das meninas brasileiras de 15 a 17 anos que abandonaram a escola já eram mães, enquanto apenas $2 \%$ das meninas brasileiras que estudavam tinham filhos.

Essa é uma realidade não só no Brasil, mas também na América Latina, pois em 2016 as mulheres latinas representavam 2/3 das jovens de 15 a 17 anos que não estudavam nem trabalhavam, e a gravidez na adolescência era considerada uma delas. A saída dessas jovens da educação precocemente é o que pode leva-las a EJA, e as responsabilidades familiares podem retira-las desse programa de educação, já que não existe apenas a responsabilidade com os estudos (SOUSA CRO, et al., 2018). 


\section{Problemas relacionados à saúde que levam à evasão escolar de jovens e adultos}

São inúmeros os fatores que causam a evasão dos jovens e adultos, entre os quais a tentativa de ganhar a vida diária para a sua sobrevivência, baixa frequência na sala de aula ou até mesmo o cansaço do dia a dia quando vão à escola, pois é desalento gera o desânimo. Há também os aspectos emocionais, sociais e psicológicos. Isso depende da situação financeira de cada região do nosso país.

Se for uma região muito pobre, o número de pessoas analfabetas e evadidas é maior, quando é uma região mais próspera o porcentual tende a diminuir, definindo o nível do analfabetismo. As altas taxas de evasão na educação de jovens e adultos brasileiros têm sido uma das grandes adversidades enfrentadas pelas redes de educação pública. A fim de compreender o que acontece de evasão, pesquisas sobre o tema constituem um dos maiores problemas analisados na educação, além do que é um fato muito preocupante (ARROYO MG, 2011).

Repensar a prática pedagógica e as causas da evasão escolar é pertinente na tentativa de minimizar o índice de alunos evadidos. Assim, deveria ser avaliada e entendida de forma mais ampla pelas políticas públicas, principalmente porque se trata de uma questão preocupante e de um tema significativo para se efetivar um estudo.

Com os altos índices de evasão escolar, caracterizada pelo abandono da escola que vem acontecendo desde a década de 1940, tem sido um dos maiores desafios enfrentados pelas redes de ensino público. Ao considerar condições favoráveis a evasão escolar, obviamente, esta questão coexiste com questões relacionadas à retenção e à repetência, tornando-se uma preocupação, o que significa uma reflexão mais ampla sobre a qualidade da educação, acesso à educação e persistência.

Essa qualidade de ensino é relacionada ao desenvolvimento social e bem-estar de um país, decidindo como, portanto, seu futuro beneficiará o crescimento econômico porque a educação é a base do desenvolvimento social (FILHO RBS e ARAÚJO RMLA, 2017).

Para Haddad CR e et al. (2011), entre os fatores que indicam a evasão, pode-se destacar: proibição dos pais de ir à escola; negligência familiar; gravidez precoce; consumo de álcool e entorpecentes; trabalho infantil; problemas de saúde; dificuldade de frequentar a escola; participação de alunos em violações; violência nas escolas; abuso ou exploração sexual.

Esses dados estão relacionados a questões fora do campus e são dignos de análise em um contexto social mais amplo. No contexto que aponta os problemas relacionados à saúde, pode-se contemplar no debate questões relacionadas à acessibilidade da pessoa deficiente até alguns tipos de doenças adquiridas pelo aluno ou por familiares, que podem procrastinar a jornada do aluno na escola.

Com relação a doenças, não somente deve-se considerar questões relacionadas à saúde do próprio aluno, mas também de familiares. Como a EJA está propícia a receber maior número jovens e adultos, o ambiente escolar precisa estar sensível às responsabilidades maiores que este grupo possui.

Quando algum familiar adoece, filho ou pessoa próxima, pode-se considerar que se trata de mais um motivo para levar ao abandono do ambiente escolar. A saúde do aluno também é importante, já que a realidade brasileira, alcançada nos últimos anos através da democratização do ensino levou muitos idosos à escola.

A pessoa idosa possui debilidades ligadas à sua saúde que pode dificultar seu acesso à educação, como doenças crônicas, e aquelas que aparecem devido à idade avançada. Dentre outros problemas enfrentados, uma série de doenças que aumentam o risco de aparecer na idade adulta, como câncer de mama, endometriose, câncer do colo do útero, câncer de próstata e etc (AURIGLIETTI RCR e LOHR SS, 2014).

A tolerância escolar é um movimento de mudança social profunda que ocorreu na sociedade nos últimos anos. Está acontecendo não apenas em nosso país, mas também no campo dos direitos humanos em todo o mundo. Envolve a mudança de atitudes quebrando a discriminação e o preconceito e respeitando as diferenças e reconhecendo que os alunos com deficiência estão no ambiente escolar enfrentando barreiras de acesso, e precisam buscar agir com persistência e participação. 
Embora mudanças significativas tenham ocorrido, é importante destacar que o campo da educação especial ainda é cercado por diversas insatisfações e ansiedades e preconiza o direito universal à educação. Fatores como esses acabam por afastar o aluno da escola, como por exemplo a não existência de rampas de acesso, facilitadores de mobilidade, banheiros adaptados e professores preparados para lidar com a diferença (RIBEIRO AC e TENTES VTA, 2016).

O bullying não pode ser descartado, mesmo se tratando de saúde, já que é um potencial devastador da saúde mental. Traumas, pânicos e depressão podem surgir em decorrência de julgamentos e linchamentos públicos. A mãe que estuda, e isso se tratando das mães precoces, recebe uma carga de julgamentos da sociedade, o aluno que se enquadra no grupo de Lésbicas, Gays, Bissexuais, Transsexuais, Travestis e outros (LGBT+), pode gerar uma série de transtornos ligados ao preconceito que sofre na sociedade, e são problemas que não surgem na ausência de saúde pública, mas que batem às portas das casas da saúde pública e causam evasão escolar (CORDEIRO AFM e BUENDGENS JF, 2012).

\section{Políticas públicas para reduzir a evasão escolar}

A Constituição Federal de 1988 garante que a educação é um direito de todas as pessoas e uma obrigação do Estado e da família. É possível encontrar na Carta Magna, artigos que estabelecem o compromisso da República Federativa do Brasil com a alfabetização e a educação como direito de todos. (BRASIL, 1988).

"A constituição apregoa que: Art. 205. A educação, direito de todos e dever do Estado e da família, será promovida e incentivada com a colaboração da sociedade, visando ao pleno desenvolvimento da pessoa, seu preparo para o exercício da cidadania e sua qualificação para o trabalho."

"Art. 206. O ensino será ministrado com base nos seguintes princípios: I - igualdade de condições para o acesso e permanência na escola; II - liberdade de aprender, ensinar, pesquisar e divulgar o pensamento, a arte e o saber; III - pluralismo de idéias e de concepções pedagógicas, e coexistência de instituições públicas e privadas de ensino; IV - gratuidade do ensino público em estabelecimentos oficiais (BRASIL, 1988). “

Além disso, o Artigo 53 do "Estatuto da Criança e do Adolescente" também estipula o primeiro direito de frequentar a escola e condições de igualdade permanente. Diante desse panorama, utilizar-se-á este artigo para apontar a relação entre evasão e violações dos direitos da criança e do adolescente, e levar em consideração as consequências dessa evasão, que dão continuidade a modelos de ensino provisórios, mas ainda hoje existentes como: a Educação de Jovens e Adultos (ALMEIDA TCO e OLIVEIRA RCS, 2015).

Para fazer jus à garantia constitucional de educação para todos, é necessário discutir propostas que colaborem para reduzir a evasão escolar na educação básica brasileira. A busca por um ambiente escolar inclusivo, que não faz nenhum juízo precipitado do aluno e que o recebe independente das diferenças, é o primeiro passo para buscar reduzir e até erradicar a evasão escolar. Tocante a isto, a única maneira de implementar métodos nas escolas, buscando alcançar esses objetivos é através de políticas públicas educacionais e estruturais, que modifiquem alguns rumos tomados pelas escolas e permita que $o$ alunado transmita à sociedade as mesmas mudanças, promovendo um movimento em massa de alterações sociais e permitindo a inclusão do diferente e das diferenças (KASSAR MCM, 2016).

Com a compreensão e o reconhecimento da diversidade da vida, o termo acessibilidade tem sido usado para garantir que todos possam acessar todas as áreas de suas vidas. Essas áreas envolvem espaço, mobiliário, equipamentos urbanos, sistemas e meios de comunicação e informação. Portanto, espera-se preparar e responder às necessidades especiais que esta diversidade pode suscitar nos ambientes. De tal forma, pode-se incluir, buscando preservar e ampliar os canais de educação do aluno deficiente, alterações em diversos campos do ambiente escolar. A pessoa deficiente que frequenta uma escola, desde a criança até $o$ adulto e o idoso, buscam um espaço inclusive e que os faça se sentir acolhido. Qualquer ação no contrário da inclusão é um passo para afastar essa pessoa do ambiente escolar, e aumentar a evasão (CORRÊA PM, 2009). 
Se tratando da gravidez na adolescência, as políticas devem girar em torno da informação e da educação em saúde nas escolas. Mesmo se tratando de uma abordagem com referência a jovens e adultos, a gravidez precoce interfere na temática quando retira adolescentes das escolas e os coloca posteriormente neste ambiente de ensino.

A responsabilidade com os filhos e com a família, também pode ocasionar a evasão na EJA, e é um problema real de saúde pública. Incluir equipes especializadas, programas de prevenção e selecionar materiais próprios para tratar assuntos da educação sexual, seria o grande avanço para combater a gravidez precoce, ainda mais considerando o histórico de desinformação e o tabu do brasileiro em tratar de assuntos relacionados ao sexo com os mais jovens (GUANABENS MFG, et al., 2012).

Uma abordagem importante para buscar reduzir a evasão de jovens e adultos quanto o assunto é doenças, é reduzir as chances de o aluno adoecer. Programas de incentivo a hábitos saudáveis de alimentação, como educação nutricional e aproximação do aluno de práticas benéficas à saúde, como a prática de esportes e o abandono do sedentarismo, tudo isso colabora para redução das chances de adoecimento do aluno.

Quando se trata do aluno jovem ou adulto, abordagens como a prevenção do uso de drogas através de programas antitabagismo, antidrogas e que vislumbram uma vida mais saudável aos seus assistidos, seria a maneira mais interessante de levar à realidade para sala de aula e buscar modificações na estrutura escolar (CERVATO-MANCUSO AM, et al., 2016).

Ações com oficinas, palestras, visitas técnicas, todas podem colaborar para alterar essa realidade. Não é necessário esperar que o aluno evada para busca-lo novamente, ou esperar que algum potencializador 0 assole para busca-lo novamente. As ações mais eficazes e com maiores chances de surtirem efeitos, acontecem no campo da prevenção.

Cuidar das salas de aula e dos alunos, incentivar que os mesmos busquem cuidar de si próprios e de suas saúdes, e trabalhar para que a educação de jovens e adultos seja cada dia menos necessária, vislumbrando um futuro onde a criança e o adolescente cumpram as etapas educacionais no tempo estipulado, garantindo assim um planejamento de vida mais estruturado, com garantias mais sólidas e passíveis de planejamento (FIGUEIREDO NGS e SALLES DMR, 2017).

\section{CONSIDERAÇÕES FINAIS}

Conclui-se com a revisão feita, que os problemas relacionados a evasão escolar na modalidade Educação de Jovens e Adultos e que estão interligados com questões de saúde, dependem de programas preventivos para serem solucionados, e que merecem uma atenção maior do poder público e da sociedade civil organizada e instruída. Todos os fatores que causam ou potencializam a evasão escolar de jovens e adultos, podem ser trabalhados na educação de crianças e adolescentes, evitando que jovens e adultos precisem voltar à escola para concluir as etapas da educação básica. $E$ as políticas que podem agir no sentido de preservar o aluno da EJA no ambiente escolar, devem girar em torno das instruções de tolerância e acessibilidade, garantindo que essas pessoas possam frequentar a escola sem serem expostas à riscos ou constrangimentos.

\section{REFERÊNCIAS}

1. ALMEIDA TCO, OLIVEIRA RCS. As causas da evasão escolar de crianças e adolescentes da educação básica e sua relação com a violação de direitos humanos. XIII Congresso Nacional de Educação - EDUCARE, 2015; 1(1): 1295412972.

2. ARROYO MG. Currículo, território em disputa. Petrópolis: Vozes, 2011.

3. AURIGLIETTI RCR, LOHR SS. A evasão e abandono escolar: causas, consequências e alternativas - o combate a evasão escolar sob perspectiva dos alunos. Cadernos PDE, 2014; 1(1): 1-21.

4. BRASIL, 1988. Constituição da República Federativa do Brasil: promulgada em 5 de outubro de 1988. 4. ed. São Paulo: Saraiva, 1990.

5. CEARON NM. Programa de Alfabetização de Jovens e Adultos - visão do aluno: uma experiência no sul da Bahia. Salvador: EDUNEB, 2011. 
6. CERVATO-MANCUSO AM, et al. Educação Alimentar e Nutricional como prática de intervenção: reflexão e possibilidades de fortalecimento. Physis Revista de Saúde Coletiva, 2016; 26(1): 225-249.

7. CORDEIRO AFM, BUENDGENS JF. Preconceitos na escola: sentidos e significados atribuídos pelos adolescentes no ensino médio. Psicologia Escolar e Educacional, 2012; 16(1): 45-54.

8. CORRÉA PM. Acessibilidade: conceitos e formas de garantia. Revista Brasileira de Educação Especial, 2009; 15(1): 171-172.

9. FAIAL LCM, et al. A saúde na escola: percepções do ser adolescente. Revista Brasileira de Enfermagem, 2019; 72(4): 964-972.

10. FERNANDES AP, CAIADO KRM. Evasão de alunos com necessidades educacionais especiais em escolas ribeirinhas: limites e desafios do atendimento educacional especializado. Revista Cocar, 2015; 1(1): 127-146.

11. FIGUEIREDO NGS, SALLES DMR. Educação Profissional e evasão escolar em contexto: motivos e reflexões. Ensaio: Avaliação e Políticas Públicas em Educação, 2017; 25(95): 356-392.

12. FILHO RBS, ARAÚJO RML. Evasão e abandono escolar na educação básica no Brasil: fatores, causas e possíveis consequências. Educação Por Escrito, 2017; 8(1): 35-48.

13. FERREIRA ABH. Mini Aurélio: o dicionário da língua português. 8, ed. Curitiba: Positivo, 2010.

14. FILHO RBS, ARAÚJO RMLA. Evasão e abandono escolar na educação básica no Brasil: fatores, causas e possíveis consequências. Educação Por Escrito, Porto Alegre, v. 2017.

15. GUANABENS MFG, et al. Gravidez na adolescência: um desafio à promoção da saúde integral do adolescente. Revista Brasileira de Educação Médica, 2012; 36(1): 20-24.

16. HADDAD CR, et al. Os motivos da evasão escolar: uma análise do programa fica. X Congresso Nacional de Educação - EDUCARE, 2011; 1(1): 1-12.

17. KASSAR MCM. Escola como espaço para diversidade e o desenvolvimento humano. Educ. Soc., Campinas, 2016; 37(137): 1223-1240.

18. MENDES MS. Da inclusão à evasão escolar: o papel da motivação no ensino médio. Estudos de Psicologia, 2013; 30(2): 261-265.

19. OLIVEIRA PCS. Evasão Escolar de Alunos Trabalhadores na EJA). Universidade Federal. Minas Gerais, 2010.

20. RIBEIRO AC, TENTES VTA. O Caminho da Escola para os Estudantes com Deficiência: o Transporte Escolar Acessível no Plano Viver sem Limite. Revista Brasileira de Educação Especial, 2016; 22(1): 27-38.

21. SOUSA CRO, et al. Fatores preditores da evasão escolar entre adolescentes com experiência de gravidez. Cadernos Saúde Coletiva, 2018; 26(2): 160-169.

22. TEODORO A. Globalização e educação: políticas educacionais e novos modos de governação. São Paulo: Cortez Editora, 2011. 